\title{
PULSIONALIDADE E CONSCIÊNCIA (BEWUßTSEIN) EM NIETZSCHE
}

\author{
[Pulsionality and consciousness (Bewußtsein) in Nietzsche]
}

\author{
Saulo Krieger ${ }^{1}$
}

\begin{abstract}
Resumo: Este artigo pretende mostrar que a consciência (Bewußtsein) em Nietzsche, ao modo de um “"conhecer' o que se pensa”, não é uma consciência de introspecção e de acesso direto a si mesma, mas de transposições e expressividade. O filósofo chega a essa concepção ao rastrear os traços básicos do ato de pensar já num nível infraconsciente, dos impulsos orgânicos. Mais precisamente, chega a um "pensamento pulsional" ao deparar com uma linguagem entabulada pelos impulsos - uma linguagem figurativa, metafórica e transposicional.
\end{abstract}

Palavras-chave: consciência; impulsos; linguagem; fisiopsicologia

Abstract: This article aims at showing that the consciousness (Bewußtsein) in Nietzsche as a "'to know' what he thinks" is not a consciousness of introspection and of direct access to itself, but a consciousness of transpositions and expressivity. The philosopher reaches this conception considering how a conscious thinking could be anticipated by an act of thinking disclosed already at the level of drives. He comes to this kind of "pulsional thinking" finding a language shared by the drives - a figurative, metaphorical, transpositional language.

Keywords: consciousness; drives;language; physiopsychology

No aforismo 354 d'A gaia ciência, Nietzsche apresenta enfim o que seria um traço definidor da consciência, ${ }^{2}$ precisamente ao propor uma correlação entre invenção de signos linguísticos e ação consciente. Não se trata de uma consciência aos moldes modernos, e isto significa, uma consciência una e idêntica a si mesma, garante epistemológico que teria por garante um laço transcendente, dotada de clareza quanto à sua ação, conteúdos e domínios, identificada aos limites de um eu. Tampouco vem a ser uma "faculdade" da consciência, à maneira de Kant, ou algo próximo ao "eu” de sua apercepção transcendental. Em sentido

\footnotetext{
${ }^{1}$ Pesquisador doutorando pela UNIFESP (Universidade Federal de São Paulo). Desenvolve pesquisa em História da Filosofia Contemporânea sobre psicologia, teoria pulsional, consciência (Bewußtsein), consciência moral (Gewissen) e conteúdo dionisíaco em Nietzsche. Possui graduação em Filosofia pela Universidade de São Paulo (1998). Tem experiência na área de Filosofia, com ênfase em História da Filosofia (Contemporânea).

${ }^{2}$ Iniciamos deliberadamente fazendo referência a um "enfim". Como se verá, Nietzsche apresenta algo que define a consciência como não o fizera em ocorrências anteriores, ou seja, nem na referência que se tem em Aurora (§ 119), nem na tematização da primeira edição d'A gaia ciência (§ 11). O presente artigo pretende mostrar como o filósofo tinha uma razão muito forte - em certa medida extratextual - para vir a trazer um traço definidor da consciência apenas na segunda edição d'A gaia ciência: precisava compreender em profundidade os aspectos presentes nas interações dos impulsos, para daí então conceber uma consciência de proveniência pulsional.
} 
contrário isso, o aforismo 354 apresenta uma consciência dessubtancializada, ${ }^{3,4}$ condicionada, ${ }^{5}$ desprovida de individualidade ou identificação inequívoca a um sujeito, ${ }^{6}$ carente de profundidade $^{7}$ e, a depender do ponto de vista, de utilidade. ${ }^{8}$

Não será preciso ir muito longe para constatar que todas essas conotações, desconcertantes por certo, advêm do modo pelo qual provém a consciência no seio da espécie humana. Tal proveniência, se por um lado lhe faz condicionada em vez de essencial, compartilhada em vez de subjetiva, superficial em vez de profunda, por outro lado, lhe impõe a marca da necessidade: imanente em vez de transcendente, a dignidade que ainda se lhe pode atribuir deriva de se ter feito necessária. ${ }^{9} \mathrm{O}$ homem que necessitava “"saber' ele mesmo o que lhe faltava, 'saber' como se sentia, 'saber' o que pensava" (FW/GC § 354, tradução ligeiramente modificada) precisou inventar signos que expressassem tal saber; estes, não era o caso de serem tal qual ele se sentia, de refletir uma impressão de modo fiel e preciso, mas precisavam ser compartilháveis. A invenção de signos e o "tomar consciência" em paralelo a esse ato inventivo é algo que abordaremos mais adiante; em primeiro lugar, atentemos ao “"saber” o que pensa”. Em sentido contrário à tendência a se tomar como coincidentes "saber" e "pensar", e a se imputar clareza e acesso imediatos a "saber o que se pensa", Nietzsche logo acrescenta: "o homem, como toda criatura viva, pensa continuamente, mas não sabe disso" (FW/GC § 354).

Com um "pensar continuamente" identificado não a uma consciência pensada como intelecto, mas referido a um animal - e o "animal mais ameaçado", devendo "exprimir sua

\footnotetext{
3 "A natureza da consciência animal acarreta que o mundo de que podemos tomar consciência, é apenas um mundo de superfícies e de signos" (FW/GC § 354).

${ }^{4}$ Para citações das obras de Nietzsche, sempre que possível damos preferência às traduções de Rubens Rodrigues Torres Filho (Nietzsche, F. "Obras incompletas", coleção Os pensadores). Nos demais casos, adotamos as de Paulo César de Souza (Companhia das Letras). Para o caso dos fragmentos póstumos, tradução do presente autor.

5 "Posso passar à suposição de que consciência em geral só se desenvolveu sob a pressão da necessidade de comunicação” (FW/GC § 354).

6 "Consciência é propriamente apenas uma rede de ligação entre homem e homem - apenas como tal ela teve de se desenvolver" (FW/GC $\$ 354)$.

7 “[...] que tudo o que se torna consciente justamente com isso se torna raso, ralo, relativamente estúpido, geral, signo, marca de rebanho [...]" (FW/GC § 354).

8 A questão da utilidade da consciência, acionada como "gênio da espécie" pelo homem ante uma necessidade que o ameaçava, vem a ser o problema trazido pelo aforismo 354: "Para que em geral consciência, se no principal ela é supérflua?" (FW/GC § 354).

${ }^{9}$ Por mais que tal necessidade não fale nem diga respeito ao ser humano considerado de um ponto de vista fisiológico ou zoológico: "O problema do ter-consciência [...] só se apresenta a nós quando começamos a conceber em que medida poderíamos passar sem ela: e é nesse começo do conceber que nos coloca a fisiologia e a zoologia" (FW/GC § 354). Em fragmento póstumo do ano seguinte ao da segunda edição d'A gaia ciência, a própria existência da consciência é negada de certo ponto de vista: "num nível puramente empírico [blo $\beta$ empirisch]: não existe nem 'espírito', nem razão, nem pensamento, nem consciência, nem alma, nem vontade, nem verdade: tudo são ficções, que se fizeram necessárias” (Nachlass/FP 14 [122], primavera de 1888).
} 
indigência" (FW/GC § 354) -, com o ser humano tomado não por um "animal racional", mas igualado a "toda criatura viva" (FW/GC § 354), entrevê-se a intenção de Nietzsche em transpor o abismo entre e corpo e consciência. Um abismo que a filosofia teria assimilado do senso comum, esmerado em justificá-lo, chegando a aprofundá-lo. Em maior ou menor grau, pode-se dizer que sempre se intuiu ou se concebeu uma lacuna entre corpo e consciência, entendidos como esferas distintas: o corpo a pertencer ao âmbito da matéria, à esfera do que a todo tempo muda e desconcerta, e isso pelo seu caráter inconstante, contraditório e fugaz. A consciência, e com ela o pensamento consciente, invariavelmente era o que tenta apreendê-lo e trazê-lo à estabilidade de um conceito e de um sentido. A alma platônica, se não era separada do corpo, mas seu complemento, dignificava-se como causa primeira dos movimentos corpóreos, possibilitando a animação do vivente. A dignidade se corroborou mesmo quando, com Aristóteles, não se viu o corpo como obstáculo, e sim "forma do corpo vivo", instrumento da alma racional, não passível de existir fora do corpo. Ou então, passando da filosofia antiga à moderna, tem-se a res cogitans, apartada da res extensa, em Descartes, separação que se mantém mesmo sob o empirismo: com Locke, ainda que o entendimento se dê às sensações como tábula rasa, a racionalidade é abonada por uma auto-identidade, e viceversa. ${ }^{10} \mathrm{E}$ prosseguindo, ainda em traços muito amplos, a questão metafísica da necessidade de algo que existe, Kant a converte em minha possibilidade de conhecê-lo, e ao problema dos juízos sintéticos a priori responde com o recurso a "faculdades" (Vermögen) - este que Nietzsche tanto ironiza. ${ }^{11}$

Contrapondo-se a essa tradição - tradição no sentido de situar um ato consciente numa sede e ponto fixo -, Nietzsche traz o ato de pensar para o nível do corpo, dissemina-o por esse corpo, e, mais ainda, concebe-o no corpo dos organismos vivos. Para tanto, seu esforço de reflexão inscreve-se no quadro do estabelecimento de uma nova psicologia, não assentada em

\footnotetext{
${ }^{10}$ Há que se considerar, no entanto, que a posição de Nietzsche de alguma forma é antecipada pela de David Hume, que aponta na mesma direção. Distanciando-se mesmo do também empirista John Locke, Hume concebe que nossos "si mesmos" [selves] "are nothing more but a bundle or collection of different perceptions, which succeed each other with an inconceivable rapidity, and are in a perpetual flux and movement. ... The mind is a theatre, where several perceptions successively make their appearance" (HUME, D. A Treatise of Human Nature. Oxford: Oxford University Press, 1978, p. 252). Assim, em Hume a mente como "teatro de percepções" seria a introspecção que se poderia ter, sem uma apercepção transcendental, como conceberá Kant. Com isso, Hume de certo modo põe em questão o pressuposto da filosofia moderna, de que haveria um si mesmo (self) uno - de caráter formal ou psicológico -, como ponto de partida metafísico a salvaguardar a racionalidade e o conhecimento. Nietzsche, se vai bem nessa direção, confere a tal concepção uma dimensão corpórea ou fisiológica, seja ela entendida como a "grande razão do corpo" (ZA/ZA, "Dos desprezadores do corpo"), seja em sua versão plural e abstrata, dos impulsos que, provisórios e hierarquizados, configuram corpo e consciência.

${ }^{11}$ Cf. JGB/BM $§ 11$, além de Nachlass/FP 30 [10], outono de 1884 - início de 1885, e 34 [183], abril-junho de 1885.
} 
bases idealistas ou metafísicas, porém calcada nos avanços da fisiologia e da neurologia de seu tempo. É certo que o filósofo não simplesmente adere a uma disciplina, seja ela a psicologia, seja a fisiologia, acedendo a seus domínios estanques, previamente dados, ou aos resultados que ela apresenta de forma bruta, não reflexiva. Isso significa que, às suas formulações, Nietzsche vai chegar não pelo puro e simples absorver dos avanços ocorridos nas ciências em questão, nem mesmo por aderir à nova psicologia francesa, científica e de traços positivistas.

$\mathrm{Na}$ verdade, ele só assumirá para si uma psicologia ao concebê-la em mútua implicação, tensão e possibilidade de distanciamento crítico, com uma fisiologia - o que chamará de "psicofisiologia" (JGB/BM § 23). Ele poderá pensar sua "psicofisiologia" em função da dimensão filosófica que empresta a psicologia e fisiologia, procedendo a uma morfologia de configurações orgânicas que não são puramente físicas e de ação mecânica, assim como o psíquico não será puramente psíquico, ao contrário do que postulava a psicologia de até então. ${ }^{12} \mathrm{Na}$ obra de Nietzsche, as formas que serão objeto da psicologia como morfologia (JGB/BM § 23), configuradas e em transformação no organismo humano, vão se traduzir em suas noções de impulsos, instintos e afetos. ${ }^{13}$

\footnotetext{
12 Deve-se ter em mente que a psicologia proposta por Nietzsche, e sua contraface na fisiologia, opõe-se à psicologia de cunho metafísico que se fazia até então. A "psicologia até agora existente" (JGB/BM § 47), além de "presa a preconceitos e temores morais" (JGB/BM § 23), não poderia ser "rainha das ciências" ou "caminho para os problemas fundamentais" (JGB/BM § 23) também por uma questão metodológica: seu método, sendo exclusivamente o da observação interior, vedava a ela a pretensão à objetividade, presa que se fazia da particularidade de seu campo de exame (seus próprios processos subjetivos) e de uma feição idealista, caudatária da dualidade metafísica representada pela oposição entre seu objeto, espiritual, e seu "não objeto", o corpóreo e material. Por isso, no Ecce homo Nietzsche pode perguntar: "Quem, antes de mim, entre os filósofos, foi psicólogo e não antes a antítese do psicólogo, 'trapaceiro superior', idealista? Antes de mim, a psicologia nem mesmo existia" (EH/EH, "Por que sou um destino?”, § 6).

${ }^{13}$ Para referir os modos pelos quais um organismo vivo interfere no meio que o cerca, reagindo a seus estímulos e ameaças, Nietzsche lança mão dos termos impulsos (Triebe), instintos (Instinkte) e afetos (Affekte). A recorrência a um ou a outro estaria amparada não por referenciais extralinguísticos, mas pela intenção de diferentes conotações: a expressão "impulsos" realçaria seu caráter ativo, de pressão ou empuxo em certa direção; "instintos”, estaria a pressupor o que nos impulsos há de memória, isto é, o que já se cristalizou como um modo certeiro de reagir a certos estímulos; com "afetos", estar-se-ia realçando sua dimensão axiológica ou avaliativa. Essa diferenciação é algo a se ter em mente, mesmo considerando que o filósofo parece não se ater a tais balizas terminológicas. Patrick Wotling ressalta o que parece ser um descompromisso do filósofo com uma terminologia fixa e faz ver que há bem outros termos com que Nietzsche se refere a "instâncias de origem infraconsciente": além de "instinto", "pulsão" e "afeto", Wotling reconhece ainda "apetites (Begierden), paixões (Leidenschaften), pendor (Hang), inclinação (Neigung) e aspiração (Streben e Verlangen) - cf. WOTLING, P. "Der Weg zu den Grundproblemen”. In: Nietzsche-Studien 26 (1997), p. 12. No presente artigo, vamos nos valer da denominação "impulsos" (Triebe), pois além de ser, dentre as três primeiras arroladas acima, a de caráter mais abrangente, é a que Nietzsche comumente usa ao tratar especificamente de sua interrelação nos fragmentos póstumos.
} 
$\mathrm{Na}$ literatura sobre os impulsos, não raro se costuma enfatizar o seu caráter agencial ${ }^{14}$ de um modo que chega a obstruir seu poder explicativo, pois assume-se esse caráter - de um impulso como o que impele - como dimensão primordial ou única. Num outro sentido, costuma-se conferir demasiada ênfase a seu caráter disposicional, e já essa vertente não dará conta do ímpeto que vai animar um organismo vivo. ${ }^{15}$ De nossa parte, pretendemos tomar distância de ambas essas unilateralidades e insuficiências, não por um desejo de contemporizar, mas por reconhecer que nos impulsos não há uma única dimensão, como nesses casos se parece pressupor, e sim duas, que vão suscitar, como veremos mais adiante, uma terceira. Elas não podem ser pensadas nem se dar separadamente, pois para se exercer cada qual pressupõe a outra. A primeira delas é a dimensão egoísta, eminentemente autocentrada, também referida por sua compulsão à autossatisfação e à descarga. Segundo o filósofo, "os impulsos [...] querem a sua satisfação" (Nachlass/FP 6 [144], outono de 1880) e, talvez mais do que isso, os impulsos são eles próprios as "fontes do prazer" (Nachlass/FP 6 [59], outono de 1880). Quanto a esse prazer, chega a ser travestido, mas é onipresente em se tratando de impulsos: Nietzsche vê os impulsos altruístas mesmo "no egoísmo rude dos animais", e, que ninguém se engane, o altruísmo seria um desdobramento, "um gênero de afirmação do próprio prazer" (Nachlass/FP 6 [163], outono de 1880). E o prazer, sensação agradável como dimensão intrínseca aos impulsos, advém de sua ação de descarga: "esses impulsos descarregam-se pouco a pouco em nossos estímulos" (Nachlass/FP 7 [15], primavera-verão 1883). Quanto ao que propriamente descarregam e lhes dará satisfação e prazer, trata-se de uma força que lhes é inerente e que armazenam (cf. Nachlass/FP 7 [239], primavera-verão 1883). Por essa dimensão, os impulsos não conhecem ponto de vista a não ser o seu próprio, e são obstinados por sua satisfação, pelo prazer que lhe proporciona sua descarga.

\footnotetext{
${ }^{14}$ A menção que aqui se faz é a um debate sobre a natureza dos impulsos em Nietzsche, que ganhou corpo na literatura anglo-saxônica, com Peter Poellner, Clark \& Dudrick e Leslie P. Thiele propondo uma visão predominantemente agencial. Cf. KATSAFANAS, P. "Nietzsche's Philosophical Psychology." In: < http://people.bu.edu/pkatsa/ActivityPassivity.pdf>, pp. 4-7.

${ }^{15}$ No mesmo debate, Cristopher Janaway, Christoph Cox, Hales \& Welshon, Brian Leiter, Robert Schacht e John Richardson, ibid., pp. 7-10.
} 
Ocorre que essa primeira dimensão seria bastante vaga se se tentasse, apenas por meio dela, dar conta dos processos orgânicos; sem falar que facilmente se incorreria numa "entificação" dos impulsos, na pressuposição de algum tipo de substrato. Mas uma vez que não há substrato, além de intrinsicamente prazerosos os impulsos são também intrinsicamente plurais. Essa pluralidade nos dá a chave para o que identificamos como sua segunda dimensão - a interacional. Ela deve entrar em linha de conta tanto quanto a dimensão de autossatisfação. Se os impulsos “não são 'unidades', mas aparentes 'estados simples” (Nachlass/FP 12 [25], verão 1883), deve-se ressaltar que eles efetivamente coincidem com sua própria interação, não sendo unidades pulsionais passíveis de interagir ou não interagir. Ora, ser equacionados a interações que se dão a todo tempo implica a negação de uma identidade que perdure no tempo - uma substancialidade. E se pensada de modo rigoroso e consequente, a não incidência em qualquer tipo de substancialidade só poderá apontar para os interstícios, para os reflexos a consistir em algo tão pouco palpável, além de condicional e provisório, quanto atrações e repulsas. No âmbito orgânico, serão elas o "a se fazer" mais próximo dos impulsos. É mediante essas mais elementares atrações e repulsas que um organismo a todo tempo se autorregula e, com isso, mantém-se vivo. ${ }^{16}$ Assim, ao pensar os impulsos como reflexos, e não como unidades ${ }^{17}$, como interstícios, e não como entes, pode-se entender sua interação não como uma qualidade entre outras, mas como dimensão constitutiva a suscitar processos que se fazem e desfazem. E não há que se pressupor entidades por trás deles, pois não haverá nem

16 Sabemos que em Nietzsche não se trata, por parte de um organismo vivo e de suas estruturas, de meramente se manter vivo. Tampouco a sobrevivência há de ser vista como um princípio teleológico. A reger tudo o que vive - e mesmo o mundo inorgânico - encontra-se a noção hipotética que o filósofo acaba por formular como "vontade de potência". Não se tem aí uma vontade que deve ser entendida no sentido tradicional, a pressupor uma carência de algo - e de algo exterior a si -, nem é o caso de se apressar em identificá-la a uma aspiração política. Tendo em vista o escopo do presente artigo, deve-se lembrar que "nossos impulsos são redutíveis a vontade de potência" (Nachlass/FP 40 [61], agosto-setembro de 1885) e que tanto nos impulsos como no "factum último" (idem) que é vontade de potência trata-se de uma potência interior e inconsciente que se quer expandir não por um sentimento de falta, mas por autoultrapassamento. Desse modo, assim como a ideia de vir-a-ser - a que faremos breve menção -, a hipótese de vontade de potência, se não é aqui tematizadas, encontra-se num pano de fundo, notadamente por redundar numa negação do princípio de identidade, que remonta a Aristóteles: se "a luta grande e pequena gira sempre em torno da preponderância, de crescimento e expansão" (FW/GC § 349), numa tendência a "ser mais ou a sentir-se como "mais"” (JGB/BM § 220), nada pode ser idêntico a si mesmo. Assim, como se verá, se todos os impulsos são animados por tal irresistível movimento de crescimento, a ideia de uma identificação a si, no tempo, e mediante a introspecção, faz-se impossibilitada.

17 A aparência de estados simples é de tal maneira enganadora que, mesmo algo que depreendemos ser tão puramente instintivo quando indecomponível, como a sensação de fome, compõe-se ela própria de "uma sensação de desprazer e [de] um saber sobre o meio de dar cabo a ela" (Nachlass/FP 12 [25], verão 1883). O filósofo observa ainda que, sem que se saiba ou se perceba, "pode-se formar uma sequência de movimentos no organismo que tenham por finalidade a eliminação da fome" (idem; grifo nosso). Essa decomposição de uma sensação que nos parece basilar e una serve aqui para sinalizar que a concepção de impulsos não pode ser simplesmente equacionada a tendências ou inclinações que, cristalizadas, impelem um organismo. Na verdade, são processos ainda mais profundos, mais plurais e mais interiores que os sentimentos de fome, dor, medo, ou o próprio instinto de autoconservação ou de conservação da espécie (cf. Nachlass/FP 6 [123], outono de 1880). 
entidades nem um "por trás". Em tal interação, se não há ordem que se possa vislumbrar, haverá sempre incontornável necessidade.

Enfim, por essas duas dimensões já temos esboçada a natureza dos impulsos que, se se sentem e se se tocam, o aforismo 354 sugere que eles próprios pensam. ${ }^{18} \mathrm{Com}$ base no pensar que se dá nessa esfera pulsional, em dado momento, e sob dadas condições, o que se entende por "consciência" vai se dar quando alguns impulsos assumem um grau de reflexividade a mais, um "saber" acerca de suas ações: quando "sabem" o que pensam (cf. FW/GC § 354). Para tanto, esse "saber" implica que alguns impulsos assumam uma posição sobranceira, que tenham privilegiada a sua perspectiva em detrimento das dos demais, ${ }^{19}$ que se façam interpretação a cumular um processo de múltiplas interpretações, conferindo ao organismo um norte em meio ao mundo que o cerca. Se, com Nietzsche, tomarmos esse mundo por um vir-aser, o organismo assim consciente será uma configuração pulsional autointerpretante que, tal como interpreta a si, interpreta esse vir-a-ser.

\section{III}

No entanto, para que alguns impulsos assumam tal posição sobranceira, a lhes conferir um "saber", o modo como interagem deve lhes proporcionar as pré-condições para isso; em outras palavras, falamos aqui das condições orgânicas que a um só tempo vão possibilitar e suscitar a consciência - o "saber" do pensar pulsional. Os impulsos continuamente pensam à medida que condicionam o que chamamos de primeira dimensão pulsional - a da autossatisfação - à segunda dimensão - a da interação. Uma vez que assim condicionada pela interação com os demais, a autossatisfação não poderia se dar de maneira cega, mas dela se demanda reflexividade - e o norte de tal reflexividade está no fato de a interação com alguns impulsos se mostrar mais prazerosa que a interação com outros. Desvelar o quanto há de reflexividade nesse prazer mais elementar foi algo que, como propomos, impeliu Nietzsche em sua reflexão sobre as interações pulsionais. Tendo em vista o que estaria em questão no

\footnotetext{
${ }^{18}$ Em fragmento póstumo de 1885 - ou seja, quando já compreendia a interação pulsional de maneira profunda , Nietzsche chega a referir esse "pensar" disseminado pelo corpo como "consciências": "O que há de notável na 'consciência' pensada como única é, precisamente, que ela se mantém fechada à pluralidade incontável das vivências dessas muitas consciências" (Nachlass/FP 37 [4], junho-julho de 1885).

${ }^{19}$ Nietzsche faz menção a esse processo em Aurora, obra de 1881, quando ainda não compreendia uma série de suas implicações e desdobramentos, como fará depois. Mas tem-se ali observações valiosas, como a que refere "só haver palavras [e consciência] para graus superlativos de processos e impulsos" (A/D § 115, tradução ligeiramente modificada), e outras, altamente figurativas, a descrever o modo como um impulso chega à consciência: "Esse impulso [ante um acontecimento] agarrou o incidente como uma presa: por que justamente ele? Porque estava à espreita, sedento e faminto" (A/D § 119).
} 
"pensar" que haveria entre os impulsos e o "saber" a franquear uma consciência pulsional, passaremos a analisar em primeiro lugar os fragmentos do período 1880, preparatórios a Aurora e também à Gaia ciência. ${ }^{20}$ Em Aurora, especificamente, não se tem uma abordagem verticalizada como as d'A gaia ciência, mas uma referência transversal à consciência como problema - para nós aqui, de tanto mais interesse por se colocar na interrelação entre processos fisiológicos e linguagem.

Nos fragmentos de 1880 a questão pulsional aparece pelo filtro de quatro tendências: a primeira delas, a maneira limitada pela qual se compreende sua interação. Isso quer dizer que a percepção recíproca mais elementar que poderia haver entre eles - alguns seriam percebidos como agradáveis, outros como desagradáveis - não se daria de forma intrínseca aos impulsos em sua condição de processos, mas em consequência do excesso (sobremedida) e obstrução em sua interrelação (Nachlass/FP 6 [110], outono de 1880); isso implica que o modo como avaliam dependeria de circunstâncias externas, como a referida obstrução no caso de uma interação que seja excessivamente buscada pelos demais impulsos. Nesse período de sua produção, a capacidade de avaliar tanto não lhes seria inerente que o filósofo chega a afirmar "todos os nossos impulsos são coloridos por nossas avaliações de valor" (Nachlass/FP 5 [1], novembro de 1882 - fevereiro de 1883). Nessa mesma direção, reconhece que entre os impulsos há de início medo e desconfiança que se convertem em transparência (Nachlass/FP 6 [297], outono de 1880, itálico nosso).

Como no caso das demais tendências, que veremos em seguida, não se trata de uma concepção equivocada, da qual se veio a abrir mão. O problema estaria na formulação pela qual, de modo latente, manifesta-se uma compreensão dos processos pulsionais mais como entes individuais e menos como interstícios interacionais. Haveria aí um resquício de substancialidade, uma propensão a atribuir aos impulsos algo de unidade última e indecomponível. Tal resquício, na verdade uma insidiosa propensão, redunda numa compreensão insuficiente do modo como interagem. A insuficiência se revela também no que pudemos isolar como segunda tendência quanto à compreensão das interações pulsionais. Se ela é observada nos fragmentos póstumos do período, revela-se sobretudo no texto da própria A gaia ciência: trata-se da relação de função. Também referida como de instrumentalização, ferramenta e tirania, será a modalidade por excelência no período 1880-1882: tal como se terá

\footnotetext{
${ }^{20}$ Deve-se ressaltar a proximidade cronológica entre as duas obras: num primeiro momento, e até agosto de 1881, Nietzsche intencionava publicar os quatro primeiro livros d'A gaia ciência (que constituem a primeira edição da obra, de 1882) a compor um segundo volume de Aurora. A esse respeito, cf. SALAQUARDA, J. "A última fase de surgimento de A gaia ciência". In: Cadernos Nietzsche 6 (1999), pp. 75-93.
} 
com a consciência no aforismo 11, o intelecto (ou a razão) seria ferramenta de nossos impulsos, que o tiranizam (Nachlass/FP 6 [31] e 6 [130], outono de 1880, 11 [115], primavera-verão de 1881, 3 [1], verão-outono de 1882). Na primeira edição d'A gaia ciência, essa modalidade revela-se incontornável à economia da espécie: "muitas hecatombes humanas ocorreram, até esses impulsos chegarem a apreender sua coexistência e a sentir que eram todos funções de uma força organizadora dentro de um ser humano" (FW/GC § 113); e para o caso das células: "é virtuoso que uma célula se transforme numa função de outra célula mais forte? Ela tem de fazê-lo. E é mau que a mais forte a assimile? Ela tem de fazê-lo também" (FW/GC § 118) - isso para não falar do tratamento dado a consciência, no aforismo 11, como se verá mais adiante.

A referida insuficiência dessa ideia de função e suas variantes, bem como das outras tendências de que se trata aqui, diz respeito precisamente à questão de conferir ao intelecto humano uma procedência alternativa à concepção tradicional. O que se intentava era uma alternativa à crença numa consciência como que inoculada por Deus, na qual vicejariam intelecto, moral, capacidade de escolha, a enobrecer o homem ante os outros animais. Descartada essa opção transcendente, ${ }^{21}$ para a opção imanente era o caso de entender de que modo um conjunto de interações em nível orgânico assentaria as condições para a consciência. Era preciso entender como, ao modo de um dispositivo natural e animal, a consciência - na verdade um "saber" os impulsos "pensavam" - teria sido suscitada para restabelecer um equilíbrio orgânico ameaçado. Para tal propósito, a modalidade de interação pulsional como função, se na verdade jamais será abandonada, revelou-se lacunar. Cumpria detalhá-la, compreender as implicações de um impulso discriminar e valorar os demais impulsos, e entender de que modo concordariam em atuar em função de um impulso mais irresistível e mais forte. ${ }^{22}$

A dificuldade, ou melhor, a insuficiência dessa modalidade de interação condiciona as outras duas tendências que se pode constatar: a terceira versa sobre a insistência com que aparece, de diferentes perspectivas, a ideia de uma depuração pulsional ou de uma inflexão

\footnotetext{
${ }^{21}$ Os fragmentos em questão direta ou indiretamente preparam A gaia ciência. E nessa obra uma concepção transcendente de consciência e, com isso, de intelecto faz-se francamente impossibilitada, até pelo anúncio da morte de Deus, no aforismo 125, e sua antecipação na denúncia da persistência de suas sombras, nos aforismos 108 e 109.

${ }^{22}$ Deve-se ter em mente que os impulsos não deixam de ser ativos, muito menos são aniquilados, mas sim são mobilizados, atuando em função de outros impulsos, que se mostraram mais fortes e irresistíveis: "na verdade todos os nossos impulsos são ativos, mas encontram-se entre si em tal ordenamento e adaptação, de caráter mesmo estatal, que seu resultado não produz nenhum fantasma" (Nachlass/FP 11 [119], primavera-outono de 1881).
} 
intelectual assumida por alguns impulsos: os impulsos incompreensíveis poderiam ser racionalizados por nossas intenções (Nachlass/FP 5 [1], novembro de 1882 - verão de 1883), tanto que a sublimação de todos os impulsos se impunha como tarefa (Nachlass/FP 6 [67], outono de 1880). A capacidade de gozo estaria resguardada, uma vez que "os impulsos modificados querem sua satisfação" (Nachlass/FP 6 [144], outono de 1880) e que "nosso saber seria uma forma atenuada de nossa vida pulsional" (6 [64], outono de 1880). Somam-se a esse quadro uma comparação do impulso científico ao da caça (Nachlass/FP 6 [374], do outono de 1880) e uma tentativa de pensar uma probidade (Redlichkeit) entre os impulsos resultante de um trabalho intelectual (6 [274], do outono de 1880). Mesmo nesse último caso, não se tem evidenciada uma passagem do pulsional ao intelectual, e a modificação dos impulsos revela-se um horizonte do que se quer compreender, e não a própria compreensão. Depreende-se que também aí se tem os impulsos como identidades a subsistir no tempo, razão pela qual haveriam de "se depurar" por si sós, tornando-se assim impulsos morais, intelectuais, de natureza lógica, sem que o filósofo pudesse explicitar como tal se daria.

Por fim, a quarta tendência: em póstumos de 1880 Nietzsche mostra interesse pela relação entre impulsos e palavras, o que não é nem acaso nem novidade: já no ensaio Sobre verdade e mentira no sentido extramoral, de 1873, tem-se sua célebre exposição sobre a relação entre impulsos nervosos e linguagem, e sua originalidade está em pensá-la sob a forma de saltos metafóricos, ou seja, de transposições. ${ }^{23}$ Anos depois, no período que

\footnotetext{
${ }^{23}$ É certo que a relação entre retórica e filosofia, do início do percurso intelectual de Nietzsche, converteu-se num prolífico interesse pelas relações entre linguagem e pensamento, entre signos e consciência - sempre com a precedência dos primeiros sobre os segundos, bem entendido. Também é certo que tal interesse não chegava a ser uma novidade. O filósofo idealista Friedrich Schelling (1754-1854) já descrevia a evolução orgânica da linguagem em paralelo com a evolução da consciência. E Eduard von Hartmann (1842-1906), seguindo Schelling, concebe uma estreita ligação entre linguagem e instinto. Se uma peculiaridade de Nietzsche deve ser reconhecida na precedência que confere à linguagem em relação ao pensamento, sua originalidade está no caráter mesmo da linguagem que propõe. Desta, o tropo por excelência vem a ser a metáfora, em seu caráter de deslocamento. Pelo padrão metafórico, figurativo, encriptado que o filósofo atribui a toda linguagem, a relação entre estímulos nervosos, linguagem e pensamento será pautada por várias transposições, segundo a célebre formulação do ensaio de 1873, Sobre verdade e mentira no sentido extramoral. De modo menos evidente e também mais intermitente, a relação entre construção retórica e pensamento far-se-á indelével em sua filosofia: ao pensar o espiritual como linguagem de sinais do corpo (Nachlass/FP 7 [126], primavera-verão 1883); em seu conceito de interpretação ao modo de um processo infinito franqueado por cada nova percepção, experiência e pensamento (cf. FW/GC 374); estreitamente afinado a este encontra-se a ideia de "pensamentos serem apenas imagens, como as palavras são apenas sinais de pensamentos" (Nachlass/FP 24 [16], inverno 1883-1884); e do pensamento ao próprio conceito de realidade, Nietzsche o faz coincidir com o de aparência (cf. Nachlass/FP 40 [53], agosto-setembro 1885 e FW/GC § 54), uma e outra sendo formas de uma atividade interpretativa . Da realidade como aparência à atividade pulsional, o que se tem são transposições interpretativas, ou seja, metáforas, e o mesmo se pode observar quanto à própria ideia de consciência: o "homem cada vez mais consciente de si" não é aquele que seria capaz de refletir seus processos com transparência e neutralidade, mas sim é "o homem inventor de signos" (FW/GC § 354). Tais signos não refletem uma "realidade", nem interior nem exterior, mas são uma transposição de sempre outros processos, a qual interessa ao inventor de signos e é condicionada por sua perspectiva.
} 
imediatamente precede as abordagens da consciência de Aurora e da primeira edição d'A gaia ciência, dão-se outras tentativas de reformular a relação entre fisiologia ${ }^{24}$ e linguagem. Ali, já sem o pendor marcadamente cético do ensaio de 1873, Nietzsche incide numa tentativa de correspondência, ainda que não fosse biunívoca, entre palavras e pensamentos (cf. Nachlass/FP 6 [362], outono de 1880). O padrão linguístico chega a render formulações elaboradas como "as palavras são como que um teclado dos impulsos, dos quais os pensamentos (em palavras) são acordes" (Nachlass/FP 6 [264], outono de 1880); também enseja interrogações e dúvidas, como quando o filósofo se pergunta de que modo uma imagem de pensamento corresponderia a palavras, já que parece não haver alavanca [Hebel] a acioná-las (Nachlass/FP 6 [361], outono de 1880). Assim, se o padrão linguístico desde cedo se mostrou baliza recorrente para Nietzsche pensar o fisiológico, não será em 1880 que tal padrão proverá uma possibilidade de mediar impulsos e consciência.

Esboçadas essas quatro tendências, mais sugestivas do que efetivas, o modo como o filósofo expressa a relação da consciência com os impulsos em Aurora inscreve-se precisamente no âmbito dessa quarta e última - de uma mediação, ela própria de caráter linguístico, entre fisiologia e linguagem. Considerando o enquadramento próprio a uma obra dotada de um escopo e também as especificidades de Aurora, seu objeto ali não seria, de modo central, as relações entre impulsos e palavras, que ali são referidas de modo transversal. Para fazer ver que não temos os acessos que pensamos ter, e que assim não sabemos o que pensamos saber no terreno da moral, em Aurora Nietzsche lança mão de recursos altamente metafóricos, referindo o corpo, em seus processos fisiológicos, como texto do qual a consciência seria ainda outro texto:

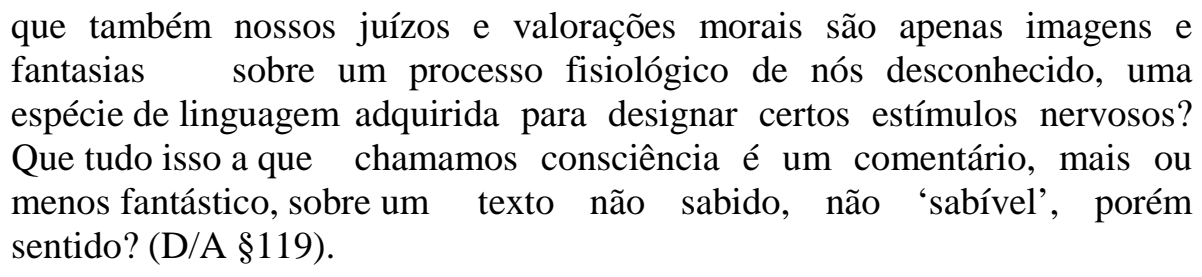

Acrescente-se, por fim, que na obra não era intenção de Nietzsche propor algo como uma "teoria da consciência". Não obstante, a consciência assim pensada, ao modo de um "comentário", permite-nos duas inferências. A primeira vem corroborar uma de nossas

\footnotetext{
${ }^{24}$ Sobre o extraordinário avanço das ciências biológicas no século XIX e a ascensão da biologia como um dos discursos dominantes na segunda metade do século, em cujo contexto insere-se o interesse de Nietzsche pela fisiologia, embriologia e outras ciências biológicas, cf. MOORE, G. Nietzsche, Biology and Metaphor. Cambridge: Cambridge University Press, 2002, pp. 1-17 e MOORE G. "Introduction", in BROBJER, T. \& MOORE G (org.) Nietzsche and Science. Aldershot: Ashgate, 2004, pp. 1-17.
} 
tônicas, a saber: era o caso conceber uma consciência sem lastro transcendente ou divino, e sim de algum modo advinda dos impulsos. Ocorre que os processos de interação pulsional ainda não estavam compreendidos - faltava-lhe uma alavanca (Hebel), para recorrer a termo usado pelo próprio filósofo (Nachlass/FP 6 [361], outono de 1880). Como segunda inferência, tem-se outra de nossas tônicas: na interação pulsional, esta que de algum modo suscitaria um grau a mais de reflexividade, intenta-se reconhecer um padrão retórico, e metafórico, a envolver transposições. As transposições ficam tanto mais evidenciadas uma vez que o "comentário" da consciência não terá compromisso em "espelhar" os processos fisiológicos, já que comentar não é reproduzir tal e qual. Embora familiar e cara ao filósofo, a ideia de uma relação entre fisiologia e transposições linguísticas mostrava-se tateante; por isso, em Aurora Nietzsche veria a consciência através de uma mediação metafórica que muito mais sugere do que dá conta da proveniência do pensar consciente.

Na Gaia ciência primeira edição (1882), onde se tem a primeira abordagem verticalizada da consciência, em seu aforismo 11, vigora o que já referimos como modalidade por excelência da interação pulsional no período: impulsos como funções de outros impulsos, como vimos esboçado em póstumos da série 6 de 1880 e na própria Gaia ciência (FW/GC $\S$ $113,116,118$, além do $\S 11$ ). Com esse padrão de interação, a relação da consciência com os impulsos só poderia ser a da tirania da primeira pelos segundos, com estes fazendo da consciência uma ferramenta deles próprios. Essa ideia pode pautar uma leitura convincente do aforismo 11, que, a despeito de seu título "A consciência", traria uma consciência bem pouco consciente e muito mais pulsional. E pela provocadora adoção de um ponto de vista dos impulsos, ficaria evidente o quanto uma consciência tida por autônoma, plena e acabada, com livre e transparente acesso a seus fundamentos e conteúdos, na verdade é suscitada e condicionada por impulsos - ali referidos pela variante "instintos" -, no que a ação pulsional e instintiva ${ }^{25}$ determinará até mesmo o modo como a consciência se equivoca e se ilude, como se concebe e se inflaciona.

Mas além dessa leitura, num âmbito mais amplo o aforismo 11 cumpre uma função num fluxo argumentativo que alinhava os primeiros aforismos da obra: se por um lado se tem

\footnotetext{
${ }^{25}$ N'A gaia ciência, Nietzsche usa tanto o termo "impulsos" (Triebe) como "instintos" (Instinkte). Ainda que não se possa dizer que esteja se valendo de uma designação rígida, as ocorrências permitem supor que esteja a usar "instintos" em referência a um conjunto de impulsos de estimulação já cristalizada pela ação da memória e por sua recorrência: precisamente no aforismo 1 os dois termos têm ocorrência próxima, segundo a qual um instinto envolveria impulsos: "nada, neles, é mais antigo, mais forte, mais inexorável, mais insuperável que esse instinto [da conservação da espécie]. [...] pois mantém [a pessoa mais nociva] impulsos sem os quais a humanidade teria há muito se estiolado ou corrompido" (FW/GC § 1; itálicos nossos).
} 
as equívocas justificações e malversações de juízos pelos homens de seu tempo, e se por outro lado se tem um mal-estar reinante, no cerne de tais atitudes, inscientes dos pesos atribuídos (FW/GC § 2) e vulgares no cálculo de vantagens (FW/GC § 3), haveria uma consciência também ela insciente e, se é a consciência dos homens de seu tempo, vulgar. Uma consciência equivocada a seu próprio respeito, a fantasiar motivos e explicações seria o cerne psíquico dos autoenganos, das explicações inconvincentes, de um mal-estar a assolar uma época. Assim, o aforismo 11 realizaria à perfeição a função de cumular o movimento dos aforismos anteriores, tanto mais que sucedido pela abordagem do objetivo da ciência e sua relação com o que chamamos de "mal-estar" (FW/GC § 12).

Por essa leitura ter-se-ia então uma consciência "inconsciente", no sentido de insciente, como seria a consciência prevalecente em seu tempo. Porém esse "não saber", que permeia a abordagem, parece admitir um duplo registro. Não obstante intitulado "A consciência", o aforismo 11 decepciona quem vai até ele em busca de um traço definidor da consciência. Como estamos a ressaltar, este só poderia ser encontrado pelo veio das interações pulsionais. E, como é provável, só seria identificável à luz de um padrão retórico, que ali não é trazido. Assim, se a modalidade de interação pulsional como função permite que se pense a relação dos impulsos com a consciência, mostrando o quanto são invasivos e o quanto pautam a percepção que ela tem de si própria, as interações pulsionais ali não permitem dar conta do trânsito entre impulsos e a consciência, entre a tarefa desta, de "incorporar o saber" (FW/GC $\S$ 11), e o que vem a ser esse "saber" em relação a impulsos, que tão-somente incorporam.

$\mathrm{O}$ que parece ser uma dificuldade a perpassar o aforismo 11 pode ser visto como consequência também de outras abordagens do espólio, e que não versam exatamente sobre a consciência, mas sobre sua contraface na constituição do sujeito. Em fragmento do outono de 1881, Nietzsche desvela mesmo nos movimentos do protoplasma um princípio que via de regra se atribuía exclusivamente à razão consciente: o princípio de identidade, na verdade o que ele chama de "erro do igual". O erro adviria das crenças básicas na existência de um persistente, igual a si mesmo e incondicionado externamente àquele que o percebe. $\mathrm{O}$ semelhante, persistente e externo àquele que percebe acaba por compor a crença no igual, que é também um juízo, a redundar no princípio de identidade, que, acrescentaríamos, pressupõe o princípio de não contradição. Assim, o que até então se tinha pela quintessência de uma racionalidade e, com isso, de uma consciência desperta, é trazido para o nível de estímulos [Reize] orgânicos - outra forma de se referir aos impulsos -, que chega a tais princípios por um interesse animal, que o faz condicionar e abreviar suas percepções: trata-se sempre de 
realçar de outro estímulo ou percepção somente o que lhe convém ou o que lhe ameaça. Essa atitude assim consciente e desperta será trazida ao âmbito da animalidade ainda uma vez, quando o filósofo observa que um sentimento de prazer e de desprazer não se relacionaria com "um conhecimento que se tem agora - mas sim a um 'conhecimento' de períodos anteriores, mais primitivos e mais longos, da humanidade e da animalidade. Estamos sob a lei do passado, isto é, de suas hipóteses e avaliações de valor". Assim, os princípios racionais mais básicos não seriam exclusividade do que se entende por consciência, e o conhecimento que se tem agora advém de hipóteses e avaliações que remontam mesmo à animalidade. Disso se conclui que as mais nobres atribuições de um pensar consciente, como o ato de valorar, o conhecer e os princípios do pensamento lógico não lhe são exclusividade. Ora, se não lhe são exclusivas já não se tem um traço definidor para pensar e referir característica tão marcante do gênero humano quanto o pensar consciente. ${ }^{26}$ Nos fragmentos dessa série, a consciência não é legitimada nem mesmo pelo que lhe seria uma função: a autoconservação da espécie não seria sua função e propósito no gênero humano, uma vez que, associando-a a um "sentimento de unidade" - ou seja, a uma subjetividade -, tal sentimento não seria necessário para que se tivesse a representação “do estranho, do maior e mais forte”, necessária à autoconservação e presente já nos organismos inferiores - portanto, "antes de surgir o sentimento de unidade da consciência" (FP/Nachlass 11 [316], outono de 1881).

As ponderações desses fragmentos, Nietzsche não as usa de pronto na obra publicada. Mas certamente as tem no horizonte por ocasião das duas abordagens da consciência d'A gaia ciência que vimos até aqui e, de outra maneira, na tematização do aforismo 354, que ainda veremos. De um modo ou de outro, elas sinalizam a dificuldade em se encontrar um traço definidor para a consciência: ao conter um protótipo da formulação de juízo, por mais que se baseie em generalização e crenças equivocadas - ou justamente por isto -, de tal maneira aproximam impulsos orgânicos e consciência, que se faz possível pensar a inutilidade dessa última: "O problema da consciência só nos aparece quando começamos a entender em que medida poderíamos passar sem ela; e agora a fisiologia e a zoologia nos colocam nesse começo de entendimento" (FW/GC § 354) - e arremata: "para que consciência quando, no principal, é supérflua?" (FW/GC § 354). Ora, se mostrar o quanto de "consciência" - de

\footnotetext{
${ }^{26}$ Isso é algo que tanto mais se deve ressaltar, uma vez que, em outros contextos, movido por intenções diferentes, o filósofo atribuirá precisamente à consciência tal caráter falseador e de abreviação. É o que se tem nas próprias abordagens da consciência n’A gaia ciência: “[...] a humanidade pereceria por seus juízos equivocados e seu fantasiar de olhos abertos, por sua credulidade e improfundidade, em suma, por sua consciência” (FW/GC § 11). E "[...] a todo tornar-se consciente está relacionada uma grande, radical corrupção, falsificação, superficialização e generalização" (FW/GC § 354).
} 
atividade desperta, racional e consciente - existe já nos estímulos orgânicos (cf. Nachlass/FP 11 [268], outono de 1881) dificulta pensar um traço definidor da consciência no caso humano, para tanto faltava encontrar um elo que desse conta da aproximação entre impulsos orgânicos e consciência, sem reduzir esta última aos primeiros. Nas formas assumidas pelas interações pulsionais, para além das generalizações e crenças aqui já assinaladas, tratava-se de encontrar os parâmetros que teriam suscitado a consciência. Isso permitiria identificar no pulsional a atividade consciente, mas de modo a prover a consciência dos desdobramentos que a distanciam do "meramente" pulsional. Em outras palavras, tratava-se de prover um continuum entre impulsos e consciência, e, no entanto, porque tal continuum nada tem de um reducionismo, um ponto de inflexão passível de diferenciar os impulsos dotados de uma reflexividade consciente.

Nietzsche sabe que a questão não será puramente orgânica, nem dependerá exclusivamente de uma "psicofisiologia dos impulsos". Para que alguns dos impulsos se tornem conscientes, como se tem no aforismo 354 d'A gaia ciência (edição de 1887), bem como no 268 de Para além de bem e mal (1886), não raro considerado "preparatório" à abordagem do 354, far-se-á necessário um fator externo e determinante: no caso do 354, uma necessidade premente e reiterada - o aforismo é marcado em grande parte pela ideia de necessidade, e nisso uma consciência supérflua revelar-se-á consciência que se fez necessária; no caso do aforismo 268 de Para além de bem e mal, sobre o surgimento da consciência do ponto de vista da linguagem, tem-se o primado de uma ameaça. Nos dois casos, portanto, temse uma violência externa a suscitar um "saber" o que sente e o que pensa, e com isso um grau de reflexividade a mais - que veio a ser a consciência. Porém tal não teria sido possível, e o ser humano sucumbiria à necessidade ou à violência, se nas interações pulsionais já não houvesse uma pré-disposição para que de algum modo se unissem frente à ameaça. O que em seu organismo havia de comunalidade entre os impulsos, que se transpusesse a uma comunalidade entre seus pares. Daí a linguagem entre os impulsos se converter em linguagem verbalmente articulada - e entenda-se, um estrato pulsional a propiciar a conversão de uma necessidade em possibilidade.

IV

Tal conversão, se aparenta ser um feito descomunal do gênero humano - e de fato o é, a ponto de o filósofo o designar por "gênio da espécie" (FW/GC § 354) - seria impossível do 
ponto de vista pulsional se os impulsos tivessem o lastro de alguma substancialidade, unidade, de uma fixidez ainda que residual e despercebidamente pressuposta. Isso porque tal lastro implicaria uma condição estática e imobilizadora, que seria um empecilho a uma possibilidade de transfiguração. E sem possibilidade de transfiguração - de transmutação de formas - tampouco poderia haver o que seria a um só tempo um continumm e ponto de inflexão entre impulsos que "apenas" pensam e os capazes de "saber" o que pensam - que serão os impulsos conscientes. Ocorre que, da parte de Nietzsche, se pensar os impulsos foi sempre algo que se pretendeu movimento contrário ao do apego à fixidez, vimos acima que tal apego reincidia de forma insidiosa, por mais que a intenção fosse se contrapor a ele. E tanto mais que a tendência a atribuir fixidez ao que não a possui expressa-se em diversos correlatos que se imiscuem no esforço de reflexão. Talvez o correlato mais evidente seja a relação causal. A causalidade é uma forma de relação que bem se presta a unidades fixas e a um modo de interação mecânico e irrefletido. Resquícios dessa relação podem ser encontrados na interação pulsional referida no fragmento 6 [110], do outono de 1880: ali, como vimos, os impulsos chegariam a tomar outros por agradáveis somente à proporção que houvesse sobremedida e obstrução na relação entre eles. Desse modo, a valoração e a hierarquia entre eles seriam fatores não inerentes e constitutivos, mas sim a posteriori (Nachlass/FP 6 [204], outono de 1880). Em póstumo do ano seguinte, ao tratar do que refere como "acontecimento altamente complexo" de prazer e desprazer, Nietzsche faz menção a "um montante de avaliações de valores e erros que estariam presentes nesse acontecimento" (Nachlass/FP 11[334], outono de 1881) - de fato estão nele presentes, mas tal constatação demandaria uma explicitação, que no caso não é formulada. O filósofo aponta uma direção, sem se debruçar sobre ela como virá a fazer depois.

Outro correlato da atribuição de fixidez é a insidiosa presunção de unidade, que se pronuncia nas frequentes menções a um processo de modificação ou depuração pulsional (FP/Nachlass 6 [64], [67], 6 [144], [32] e 6 [274] e 6 [370] do outono de 1880, 11 [124], outono de 1881). Pelo modo como era pensado e referido, tal processo se daria nos impulsos tomados individualmente. Da mesma forma, impulsos como unidades últimas $e$ indecomponíveis são algo que se depreende da referência a "impulsos sem pensamento" e “impulsos com pensamento" (Nachlass/FP 6 [265], outono de 1880). Isso também se aplica às tentativas de, de algum modo, fazê-los corresponder a palavras (Nachlass/FP 6 [264] E [362], outono de 1880). E mesmo a relação de interação restringindo-se a função, tal como se apresenta na primeira edição d'A gaia ciência, faz-se tributária de uma concepção dos 
impulsos como unidades: pela reincidência em unidades que se submeteriam a outras unidades, fazendo-se função das mais fortes, a Nietzsche não era possível adentrar os meandros desse processo, como viria fazer precisamente entre 1884 e $1886 .^{27}$

Assim, o que em 1880-1882 se pode ter por tentativas passa por reelaborações, convertendo-se em vias efetivas para se pensar um continuum entre corpo - sob a forma dos impulsos - e consciência. É de modo sintomático que já em 1883 eles são pensados em sua maior complexidade: sendo-lhes pouco a pouco vedada a unidade, passam a ser entendidos como "órgãos mais elevados", no sentido de "ações, impressões e estados conjuntos de sensações que crescem juntos, organizando-se, nutrindo-se" (Nachlass/FP 7 [198], primaveraverão de 1883). Nessa mesma direção, Nietzsche reconhece que "todos os impulsos, de anseio, de repulsa etc. não são 'unidades', mas aparentes 'estados simples"” (Nachlass/FP 12 [25], verão de 1883; itálico nosso). E a compreensão dos impulsos em paulatina depuração faz reconhecer os impulsos já não ao modo de mal disfarçadas "entidades", mas ao que vai pautar ações e movimentos nas estruturas orgânicas, histológicas, citológicas. Nessa medida, os impulsos já não serão materialmente identificados e à obstrução ou atração por outros impulsos (cf. Nachlass/FP 6 [110], outono de 1880), mas serão equacionados a um decidir sobre o emprego de sua força (cf. Nachlass/FP 7 [239], primavera-verão de 1883) e também a um sentir: "Cada um desses impulsos se sentirá, em vista de cada outro, obstruído ou incitado, adulado" (Nachlass/FP 1 [58], outono de 1885 - primavera de 1886; itálico nosso). À medida que a depuração pulsional faz migrar o olhar do filósofo das manifestações externas ao que seria sempre mais interior, os impulsos passam a ser pensados como intrinsicamente valorativos. E identificá-los ao ato de valorar é não empenhar seu prazer e sua dor como dependentes da fruição ou da obstrução por outros impulsos, mas como a atuar eles próprios "ao modo de um sistema de juízos de prazer e de dor" (Nachlass/FP 25 [460], primavera de 1884). Desse modo, os impulsos não serão identificados nem mesmo a uma decomposição das atividades orgânicas, mas aos interstícios que as impelem, que as sustentam ou podem evitá-las, que as fazem "arranjar-se e ordenar-se em atividades superiores e inferiores, a um obedecer que, incessantemente repetido, não é cego, muito menos mecânico, é um obedecer selecionador, esperto, ponderado, ele próprio relutante" (Nachlass/FP 37 [4], junho-julho 1885; tradução modificada).

\footnotetext{
${ }^{27}$ Sobre o processo de depuração pulsional pela via do reconhecimento de sua natureza linguística no período 1884-1886, cf. WOTLING, P. “What Language Do Drives Speak?”. In: BRANCO, M. J. M. \& CONSTÂNCIO, J. (org.) Nietzsche on Instinct and Language. Berlin/Boston: De Gruyter, 2011.
} 
Com essa reelaborada concepção dos impulsos, por certo eles continuam a ser fontes de prazer ou "impulso para algo bom” (Nachlass/FP 26 [72], verão-outono de 1884), nesta que aqui isolamos como primeira dimensão, assim como mais e mais vão apontar para as interações - as quais chamamos aqui de sua "segunda dimensão". Porém, a essas duas dimensões vem se acrescentar uma terceira, que agora desvelamos: à medida que de "fontes de prazer" eles são capazes de adiar esse prazer, fazendo-se promessas de prazer (cf. 7 [239], primavera-verão 1883), e à medida que em vez de coincidir com sua prazerosa descarga, podem tê-la no horizonte, fazendo-se impulsos "para algo bom, de algum ponto de vista" (Nachlass/FP 26 [72], verão-outono de 1884, itálico nosso), a segunda dimensão efetivamente condiciona a primeira. A resultante que se terá daí não redundará em nenhuma delas: nem interação, muito menos uma prazerosa descarga. Trata-se de terceira dimensão, que se pronuncia de forma bastante clara na identificação dos impulsos a avaliações de valor (cf. Nachlass/FP 25 [460], primavera de 1884). E nós a tomamos por terceira dimensão uma vez que, para efeito de uma análise dos impulsos, o ato de avaliar não coincide com interagir e muito menos com uma fonte de prazer.

Mas o que assim chamamos terceira dimensão pulsional não se evidencia como mero exercício de abstração. Ela é realmente um estado engendrado pela suspensão das outras duas dimensões. É instaurada mediante o retardo da descarga pulsional, por um lado, e a antecipação das interações possíveis, por outro. A terceira dimensão é um domínio em que, no seio mesmo das satisfações e interações pulsionais, satisfações e interações se fazem, porque suspensas, abstraídas. À medida que abstraídas, são substituídas pelos traços comuns a grupos de impulsos e a interações possíveis que serão evitadas, aguardadas ou postergadas. Com isso, toda e qualquer interação pulsional já não se daria por "impulsos em si”, mas pelo que neles possa haver de compartilhável e compreensível: relações de força numa hierarquia, de comando e obediência, de luta e colaboração. ${ }^{28} \mathrm{Na}$ terceira dimensão pulsional, os impulsos convertem-se nos valores que lhes são atribuídos por outros impulsos, e nessa medida são uma transposição de si próprios na percepção dos demais. Em outras palavras, tem-se uma fixação de hierarquias pulsionais e sua colocação em outro plano, no qual as

\footnotetext{
${ }^{28}$ Nietzsche recorrerá à metáfora das forças para dar conta do aspecto quantitativo do que se nos dá como realidade. Deve-se atentar para o fato de com "forças" o filósofo ter em vista menos a acepção de violência, e mais a de organização entre os impulsos. Tal conotação quantitativa, ainda que propriamente ausente nas conotações de impulsos, afetos e instintos, faz-se sentir nas interações entre eles, uma vez que a pressão de maior ou menor força vem a ser um padrão de comunicação: pela maior ou menor força, os impulsos entendem se é o caso de pressionar, resistir, evitar ou aderir, se é o caso de comandar ou obedecer (cf. Nachlass/FP 34 [123], abril-junho de 1885).
} 
interações não propriamente se dão, mas são valoradas por antecipação. E se toda interação pulsional converte-se em fixação e transposição de traços compartilháveis, antecipa-se na esfera dos impulsos o "fixá-las [das impressões de nossos sentidos] e como que colocá-las fora de nós" (FW/GC § 354) - afinal de contas, a impressão provocada por outros impulsos será algo transposto para a valoração desses impulsos, que vai sempre antecipá-los e condicioná-los.

É desse modo que a terceira dimensão pulsional deixou o homem na antessala da atribuição de signos, pela qual nele se engendrou a consciência. Pela terceira dimensão pulsional os impulsos valoram os demais e, ao fazê-lo, além de os transpor, abreviam-nos em forma de traços que se mostram relevantes, simplificando-os. Mas deve-se observar que tal esforço não é apenas de transposição, abreviação e simplificação, porém todo ele é uma invenção - assim como a linguagem humana transpõe, abrevia, simplifica, e o faz como invenção. Desse modo, entre os impulsos ter-se-ia uma comunicação, uma pré-linguagem a propiciar uma linguagem que se fez verbal, acionada como "gênio da espécie" por ocasião de uma reiterada necessidade. Com a linguagem verbalmente articulada, a transposição, se já havia entre os impulsos, é multiplicada de maneira exponencial: se já os impulsos não interagiam de modo puro e simples, em contato direto, ingênuo, no caso do animal humano multiplica-se o processo de expropriação: mais ele inventa signos, mais fenômenos ele pode abarcar à sua volta, e com isso mais ele depura, faz assumir ares etéreos, a configuração pulsional que o constitui.

Se a psicologia como perscrutação da morfologia dos impulsos (cf. JGB/BM § 23) se fez via para a concepção, por Nietzsche, da consciência, vimos que a linguagem desde sempre se lhe ofereceu como padrão de decifração. Esse padrão, se não é fortuito, tampouco deixa de ser condicionado por sua formação de filólogo, sendo assumidamente hipotético. Na verdade, por mais que se mostre fecundo, ele só pode mesmo ser hipotético, até pela concepção de linguagem por Nietzsche - metafórica, figurativa, transposicional. Se o único acesso possível se dá por uma linguagem encriptada, e não pela expressão transparente, a introspecção, mais do que dificultada, na verdade perde todo o sentido. Proceder à introspecção demandaria linguagem, e uma linguagem da qual se imagina transparecer, em vez de transpor e inventar. Mas para Nietzsche, o maior problema não está em a linguagem não transparecer, embora acreditar-se transparente lhe seja uma ilusão a mais. O problema é que a linguagem, se converteu necessidade em possibilidade, se num primeiro momento foi inventiva, logo se aferrou a seu generalizar, vulgarizar, simplificar, tornar compartilhável, expropriando de si as 
vivências, a todo tempo tornadas comuns. A linguagem, quando pura e simplesmente repetida, entendida como idêntica a si mesma, a referir "coisas" e coisas idênticas, atua no sentido contrário a um "saber o que pensa". Nesse sentido ela apenas pensa, com o agravante de se imaginar um saber privilegiado - tem-se aí a consciência intermitente, do aforismo 11, ou a consciência como doença, do aforismo 354, que se limita a replicar signos, sem inventálos, e isto significa, sem se fazer consciente deles, de sua própria ação e de si mesma.

À medida que expropriadas por um quase automatismo linguístico, as vivências pulsionais remeteriam a um problemático "si mesmo" para Nietzsche. ${ }^{29}$ Neste, uma tradição moderna aprendeu a encontrar os ecos de uma consciência identificada a um sujeito com acesso direto e privilegiado a si e, a partir daí, a um mundo refletido pela chave de sua subjetividade. Pois para Nietzsche um "si mesmo" seria uma ficção reguladora - obviamente não verdadeira, mas uma miragem conveniente a nortear nossa relação com o mundo. De modo mais rigoroso, porém, um "si mesmo" seria uma contradição em termos: o "mesmo" seria uma crença a pautar um "si" que não se repete, mas a todo tempo se transfigura. Está claro que este não seria regido por uma identificação - que já não cabe quando "ser" é substituído por um vir-a-ser -, e por isso um "si” não poderia residir numa autoidentificação por parte da consciência ou do intelecto. Intersticial, o "si" estaria, tal como se tem ao nível dos impulsos, nas interações: nas interações de uma provisória configuração pulsional com o meio que a cerca. E o "mesmo" seria ali uma valoração conveniente imputada à própria configuração, ao modo da terceira dimensão dos impulsos.

Se o sucedâneo de um "si mesmo" da tradição é um "si”" que a todo tempo se transfigura, o acesso a ele é questão que, em Nietzsche, não se pode colocar, pois também tal acesso pressuporia um "si" identificado a um "si mesmo". Uma descabida tentativa de acesso valer-se-ia de padrões linguísticos comunalmente ratificados, e o externamente mediado só faria expropriar mais e mais a aparente introspecção, sempre trazida aos referenciais comuns e à superfície. Para um "si” que a todo tempo transfigura o seu "mesmo", o que se pode ter é a expressividade. Algo próximo do que o próprio filósofo, em sua obra, vivenciou. Por sua experimentação com o pensar, pelas hipóteses deliberadas e pela inventividade formal e linguística, Nietzsche acima de tudo expressou sua transfiguradora configuração pulsional. Não como tentativa de acessá-la ou por receio de desencontrá-la, mas, em consonância com

\footnotetext{
${ }^{29}$ Para uma abordagem alternativa de um "si mesmo" em Nietzsche - altamente contextualizada e que não o descarta de modo terminante, cf. EMDEN C. Nietzsche on Language, Consciousness, and the Body. Urbana e Chicago: University of Illinois Press, 2005, pp. 112-123.
} 
ela, procurou sempre se retomar revigorado e mais potente - como alguém que não se identifica ao que já foi, mas se torna o que se é.

\section{Referências bibliográficas}

NIETZSCHE, F. Sämtliche Werke - Kritische Studienausgabe (KSA). Edição organizada por Giorgio Colli e Mazzino Montinari. Berlim: Walter de Gruyter \& Co., 1988, 15 vols.

Obras incompletas. Trad. Rubens Rodrigues Torres Filho. 2. ed. São Paulo: Abril cultural, 1978 (Col. "Os Pensadores").

. A gaia ciência. Trad. Paulo César de Souza. São Paulo: Companhia das Letras, 2011.

. Aurora. Trad. Paulo César de Souza. São Paulo: Companhia das Letras, 2008.

- Genealogia da moral. Trad. Paulo César de Souza: Companhia das Letras, 2006.

. Ecce homo. Trad. Paulo César de Souza. São Paulo: Companhia das Letras, 2010.

EMDEN, C. J. Nietzsche on Language, Consciousness and the Body. Urbana/Chicago: University of Illinois Press: 2005.

HUME, D. A Treatise of Human Nature. Oxford: Oxford University Press, 1978, p. 252).

MOORE, G. Nietzsche, Biology and Metaphor. Cambridge: Cambridge University Press, 2002.

"Introduction", in BROBJER, T. \& MOORE G (org.) Nietzsche and Science. Aldershot: Ashgate, 2004, pp. 1-17.

WOTLING, P. “Der Weg zu den Grundproblemen”. In: Nietzsche-Studien 26 (1997). 